\title{
Real-Time PCR for Detection and Identification of Anguina funesta, A. agrostis, A. tritici, and A. pacificae
}

Wenbin Li, Zonghe Yan, and Mark K. Nakhla, United States Department of Agriculture (USDA) Animal and Plant Health Inspection Service, Center for Plant Health Science and Technology, Beltsville Laboratory; and Andrea M. Skantar, Nematology Laboratory, USDA Agricultural Research Service, Beltsville, MD 20705

\begin{abstract}
Li, W., Zonghe, Y., Nakhla, M. K., and Skantar, A. M. 2015. Real-time PCR methods for detection and identification of the nematodes Anguina funesta, A. agrostis, A. tritici, and A. pacificae. Plant Dis. 99:1584-1589.

A number of seed, leaf, and stem gall nematodes are of significance to the forage and landscape grass and livestock industries. In North America, the bentgrass nematode, Anguina agrostis, reduces seed production on Agrostis tenuis and several other grass species. Anguina funesta is a seed-gall nematode that is most significant for its association with the toxigenic bacteria Rathayibacter toxicus. The wheat seed gall nematode A. tritici causes significant damage to wheat and other cereals; although it has been found in many countries worldwide, it has not been detected in the United States since 1975. Molecular methods based upon sequence variation in the ribosomal internal spacer region are useful for

accurate identification of Anguina spp. Described herein are new speciesspecific primers and TaqMan probes for real-time polymerase chain reaction (PCR) identification of A. agrostis, A. funesta, A. tritici, and A. pacificae. Primer and probe combinations were each specific for the intended species and were sensitive enough to detect as few as 1.25 copies of nematode ribosomal DNA. PCR was also specific and sensitive in duplex assays that included genus-specific internal control primers as well as species-specific primers and probes. These standardized realtime PCR protocols should facilitate fast and accurate identification of Anguina spp. by diagnostic laboratories.
\end{abstract}

Anguina funesta Price, Fisher \& Kerr, 1979, A. agrostis (Steinbuch, 1799) Filipjev, 1936, A. tritici (Steinbuch, 1799) Filipjev, 1936, and A. pacificae Cid del Prado Vera \& Maggenti, 1984 are among the most significant seed, leaf, and seed or stem gall nematode species of current or emerging importance in North America. The seed gall nematode $A$. tritici was the first plant-parasitic nematode observed by any scientist and was described in 1743 by a Catholic clergyman, John Turberville Needham, who reported its occurrence in wheat seed to the Royal Society of London (23). This is thought to be the first recorded microscopic observation on the association of a pathogenic organism with a plant disease (9).

A. tritici exists in many of the major cereal-growing regions throughout the world. Prior to adoption of mechanical and cleaning procedures to produce high-quality, clean seed, this nematode caused heavy economic losses to its most frequent host, wheat (Triticum aestivum L.). Infected heads of wheat are usually shorter than healthy ones, and the symmetry of the head is destroyed because the galls force the glumes to spread apart and alter the position of awns (9). The nematode may also cause a problem on rye (Secale cereal L.) and other species in the genus Triticum. Unlike galls caused by A. funesta or A. agrostis, seed galls caused by A. tritici are smaller than normal seed. Although previously reported in California, Georgia, Maryland, New York, North Carolina, South Carolina, Virginia, and West Virginia, A. tritici has not been found in the United States since 1975 (D. J. Chitwood, personal communication; United States Department of Agriculture [USDA] Nematode Collection entries 6126, 6588, 15365, and 15368).

A. funesta is the vector for Rathayibacter toxicus Riley \& Ophel 1992 (syn. Clavibacter toxicus), a bacterium that interacts with the

Corresponding author: A. M. Skantar; E-mail: andrea.skantar@ars.usda.gov

Mention of trade names or commercial products in this publication is solely for the purpose of providing specific information and does not imply recommendation or endorsement by the United States Department of Agriculture.

Accepted for publication 29 April 2015.

http://dx.doi.org/10.1094/PDIS-09-14-0959-RE

This article is in the public domain and not copyrightable. It may be freely reprinted with customary crediting of the source. The American Phytopathological Society, 2015. annual ryegrass (Lolium rigidum L.) to produce corynetoxins. When infected grasses are consumed, animals suffer neurological symptoms, toxicosis, and death $(2,17)$. The nematode and the vectored bacterium were first associated with toxicity of annual ryegrass in Manoora, Australia in 1978 (5). In the year after the very first detection of association, 5,591 sheep and 232 cattle died on infested pastures there (6). This animal toxicosis could present a threat to the United States livestock industry (worth over $\$ 95$ billion for cattle and over $\$ 836$ million for sheep in 2008) (National Agricultural Statistics Service, http://www.census.gov/compendia/statab/2012/tables/12s0870. pdf). Therefore, $R$. toxicus is considered a select agent by USDA Animal and Plant Health Inspection Service (www.selectagents.gov). The nematode can develop galls in undifferentiated flower buds, stamen cells, and various other tissues, including seed. Nematodes mature and reproduce within the galls, producing second-stage juveniles that are highly resistant to drying. The bacterium $R$. toxicus may remain within the nematode gall or may grow outside of it to encompass other parts of the head. In the latter case, yellow bacterial slime may be evident on the nematode galls, which are larger than normal seed and readily detectable. However, similar nematode galls may be induced by A. agrostis in ryegrass (20).

Although the problem of ryegrass toxicity is primarily confined to Australia and South Africa, there were reports from Oregon of similar symptoms from the 1940 s to the 1960 s $(16,17)$. Bacterial head blight of orchardgrass (Dactylus glomerata L.), caused by nontoxigenic $R$. rathayi, exhibits superficially similar symptoms and is vectored by an uncharacterized Anguina sp. (1). Therefore, molecular characterization of undescribed Anguina spp. is needed for identification of these nematodes and to further define boundaries of species associated with these potentially harmful bacteria.

A. agrostis is a potentially important pest where bentgrasses in the genus Agrostis are grown for seed (9). This nematode has a wide distribution worldwide and has been reported in the United States (4). The second-stage juveniles of A. agrostis from seed or soil move in a film of water to feed on the growing points of young plants. When inflorescences form, nematodes enter the tissue of developing ovules and induce seed galls. The infected seed gall inflorescences have glumes that are four to five times longer than normal seed. Seed galls containing nematodes are dark brown in color compared with uninfected seed; hence, they can be separated manually via visual inspection. 
A. pacificae is the most devastating pest of Pоа апnиa L. putting greens in northern California golf courses. The nematode is a major threat to the California golf industry, which supports 160,000 jobs and annually contributes more than $\$ 6$ billion directly to the economy (12). Stem galls form at the crown of the plant, which contains developing juveniles, adults, and eggs; a second generation of the nematode may follow. Initial symptoms on turf caused by the nematode are yellow patches of about $5 \mathrm{~cm}$ in diameter, which enlarge and may coalesce as the nematodes spread. Young infected plants may die and, when the infestation is severe, a rough, uneven putting surface may result.

Within the United States, nematodes that are intercepted at ports of entry or found during soil sampling and suspected to be from the genus Anguina are routinely submitted to the USDA Agricultural Research Service (ARS) Nematology Laboratory in Beltsville, MD, where species identification is typically achieved through morphological examination and confirmed through sequencing of the ribosomal RNA (rRNA) internal transcribed spacer (ITS) gene. This entire process is labor intensive and time consuming but, in many cases, it provides the most definitive identification. Another common approach for molecular identification of Anguina includes polymerase chain reaction (PCR) restriction fragment length polymorphism (RFLP) of the ITS1 rRNA gene (15). Distinct patterns of restriction fragments generated by the enzymes $A l u \mathrm{I}, B s r \mathrm{I}, E c o$ RI, HaeIII, HhaI, HinfI, and TaqI can discriminate among A. agrostis, A. funesta, A. pacificae, A. tritici, A. wevelli, A. agropyronifloris, A. microlanae, and several other unnamed species isolated from specific host plants (15). PCR-RFLP was used in 2010 to confirm, for the first time, the presence of $A$. funesta in the United States, discovered in ryegrass from Oregon (13). Although the patterns can be species specific, PCRRFLP lacks the sensitivity and speed of real-time PCR that is often favored for rapid diagnostic and quarantine applications $(3,14,18,24,25)$. The objective of this study was to develop and validate fast and robust TaqMan real-time PCR methods for accurate detection and identification of these four nematode species in the genus Anguina.

\section{Materials and Methods}

Nematode sources and DNA extraction. Nematodes used for sequencing were from previously known Anguina populations listed in Table 1 . Single nematodes were mechanically disrupted with sharp forceps in $20 \mu \mathrm{l}$ of nematode extraction buffer (22) and stored at $-80^{\circ} \mathrm{C}$. DNA extracts were prepared by thawing frozen nematodes, to which an additional $1 \mu$ l of proteinase $\mathrm{K}(2 \mathrm{mg} / \mathrm{ml}$ stock solution) was added. The tubes were incubated at $60^{\circ} \mathrm{C}$ for $60 \mathrm{~min}$, followed by $95^{\circ} \mathrm{C}$ for $15 \mathrm{~min}$ to inactivate the proteinase $\mathrm{K}$. Extract $(2 \mu \mathrm{l})$ was then used for conventional and real-time PCR.

Conventional PCR. Amplification of the rRNA region that includes ITS1, 5.8S rRNA gene, and ITS2 was performed using the primers and conventional PCR protocol described previously (19). Briefly, the primers TW81 (5'-GTTTCCGTAGGT GAACCTGC-3') (8) and AB28 (5'-ATATGCTTAAGTTCAGC GGGT-3') (7) were included at $0.2 \mu \mathrm{M}$ each in reactions containing 2 to $3 \mu \mathrm{l}$ of extracted nematode DNA, $200 \mu \mathrm{M} \mathrm{dNTP,} 1 \mathrm{U}$ of Platinum Taq DNA polymerase (Invitrogen, Carlsbad, CA), and supplied enzyme reaction buffer in a total volume of $25 \mu$ l. Cycling included one step of $95^{\circ} \mathrm{C}$ for $2 \mathrm{~min}$; followed by 35 cycles of $95^{\circ} \mathrm{C}$ for $30 \mathrm{~s}, 55^{\circ} \mathrm{C}$ for $30 \mathrm{~s}$, and $72^{\circ} \mathrm{C}$ for $90 \mathrm{~s}$; and finished with one cycle at $72^{\circ} \mathrm{C}$ for $5 \mathrm{~min}$. PCR products were excised from agarose gels and purified with the QIAquick Gel Extraction Kit (Qiagen, Valencia, CA). The concentration of DNA was determined with a NanoDrop spectrophotometer (Thermo Scientific, Wilmington, DE). Sequencing of PCR amplicons was performed at the University of Maryland Center for Biosystems Research (College Park). GenBank accession numbers for newly obtained sequences are listed in Table 1.

Separate amplicons for each species ITS fragment were generated and cloned into the TOPO TA pCRII vector (Invitrogen) to be used as template for quantitative real-time PCR standard curves. Plasmid clones were propagated in strain Mach1-T1 of Escherichia coli (Invitrogen) and purified using PureLink Qick Plasmid Miniprep kits (Invitrogen). The cloned plasmids were named AF1247 (1,247 bp of A. funesta), AA1083 (1,083 bp of A. agrostis), AT902 (902 bp of A. tritici), and AP908 (908 bp of A. pacificae). Cloned plasmid DNA concentrations were measured by NanoDrop spectrophotometer. The number of copies of each rDNA insert was determined using the calculation: number of insert copies $=$ [amount of DNA (ng) $\times$ $\left.6.022 \times 10^{23}\right] /\left[\right.$ insert length $\left.(\mathrm{bp}) \times 1 \times 10^{9} \times 660\right]$. The initial concentrations were adjusted in Tris-EDTA buffer to $5.0 \times 10^{8}$ copies $/ \mu 1$. Tenfold serial dilutions were prepared in triplicate to establish standard curves for quantitative real-time PCR assays.

Primer and probe design. ITS rDNA sequences from $A$. funesta (AF396349), A. agrostis (AF396343), A. tritici (AF396354), and A. pacificae (A. M. Skantar unpublished) was analyzed with IDT PrimerQuest online primer design software (IDT, Coralville, IA; http://www.idtdna.com/Primerquest/Home/Index). Anguina genusuniversal TaqMan probe and primers were designed from the $5.8 \mathrm{~S}$ rRNA region, and the Anguina spp.-specific primers and probes were based on ITS2 (Table 2). The specificity of primers and probes was checked by alignment with sequences from additional reference populations: A. funesta from Australia (GenBank accession numbers AF396347 and AF396348); A. agrostis from Belgium (AF396338), Oregon (AF396339), Russia (AF396340, AF396341, and AF396344), and New Zealand (AF396342); A. tritici from Australia (AF396354), India (JF826515 and JF826516), Syria (DQ151460), China (AM888392), and an unknown location (AF396353); and A. pacificae from California (KM114440) using Sequencher 5.0 (Genecodes Inc., Ann Arbor, MI). Primer specificity was further analyzed in silico by comparison with several other Anguina DNA sequences from GenBank. This served to expand the comparison with named and unnamed Anguina spp. that were not available for direct testing by real-time PCR. The primers and probe sets were screened for target specificity in real-time PCR using DNA from two populations of A. funesta, one $A$. agrostis, three $A$. tritici, and one $A$. pacificae. In addition, two species of stem and bulb nematodes (Ditylenchus dipsaci and D. destructor), one species of foliar nematode (Aphelenchoides fragariae), five species of root-knot nematodes (Meloidogyne spp.), two lesion nematodes (Pratylenchus spp.), and one dagger nematode (Xiphinema sp.) were used as controls (Tables 3 and 4).

Table 1. Newly obtained sequences for the internal transcribed spacer region of ribosomal RNA of different Anguina spp.

\begin{tabular}{|c|c|c|c|c|c|}
\hline Species & Sample ID & Origin & Source & Host & Accession \\
\hline \multirow[t]{2}{*}{ Anguina agrostis } & 70E1, E2, E3 & Oregon & Fraley & Bentgrass & KM114436 \\
\hline & 74A2, A3 & Oregon & McClure & Bentgrass & KM114437 \\
\hline \multirow[t]{3}{*}{ A, funesta } & 49F1, F2, F3 & Oregon & Fraley & Ryegrass & KM114435 \\
\hline & 70F1, F2, F3 & Australia & Fraley & Ryegrass & KM114438 \\
\hline & 74D9, D19, D11 & Australia & McClure & Ryegrass & KM114439 \\
\hline A. pacificae & $74 \mathrm{C} 7, \mathrm{C} 8, \mathrm{C} 9$ & California & McClure & Bluegrass & KM114440 \\
\hline \multirow[t]{3}{*}{ A. tritici } & 74B4, B5, B6 & Mexico & McClure & Wheat & KM114443 \\
\hline & 16A5, A6, B6 & Virginia & Authors & Wheat & KM114445 \\
\hline & $16 \mathrm{C} 4, \mathrm{C} 5, \mathrm{C} 6$ & North Carolina & Authors & Wheat & KM114444 \\
\hline \multirow[t]{2}{*}{ Anguina sp. } & 70G10, G11, G12 & Idaho & McClure & Sand dropseed & KM114441 \\
\hline & 70H7, H8, H9 & Oregon & McClure & Orchard grass & KM114442 \\
\hline
\end{tabular}


Real-time PCR. To obtain high endpoint fluorescence and low cycle threshold $(\mathrm{Ct})$ values, optimization of all reagents, including the concentrations of the target or internal control primers and probes, $\mathrm{MgCl}_{2}$, and dNTPs, and standardization of the amplification protocol, including the temperatures and times of denaturation, annealing, and amplification, were carried out with serial 10-fold dilutions of DNA prepared from single nematodes of each Anguina spp. After optimization, the real-time PCR amplifications were performed using a SmartCycler II (Cepheid, Sunnyvale, CA) in a 25- $\mu 1$ reaction volume consisting of $240 \mathrm{nM}$ each target primer, $160 \mathrm{nM}$ each positive internal control primer, $120 \mathrm{nM}$ each TaqMan probe, $6.0 \mathrm{mM}$ $\mathrm{MgCl}_{2}, 240 \mu \mathrm{M}$ each dNTP, $1 \times$ PCR buffer, and $1 \mathrm{U}$ of Platinum Taq DNA polymerase (Invitrogen). The standard amplification protocol was $95^{\circ} \mathrm{C}$ for $20 \mathrm{~s}$ with optics off, followed by 40 cycles at $95^{\circ} \mathrm{C}$ for $1 \mathrm{~s}$ with optics off and $60^{\circ} \mathrm{C}$ for $40 \mathrm{~s}$ with optics on and a temperature ramp at $5^{\circ} \mathrm{C} / \mathrm{s}$ for the whole protocol. All reactions were performed twice and each run contained one positive control and one negative control (water). The data were analyzed using the SmartCycler software, version 2.0D. Standard curves were constructed from real-time PCR performed with serial 10-fold dilutions of DNA template prepared from Anguina agrostis, A. funesta, A. pacificae, and A. tritici (Table 5). Standard linear regressions $(Y=a+b X)$ of the log concentration of the template copies $(Y)$ versus the mean $\mathrm{Ct}$ values $(X)$ were obtained. PCR amplification efficiency (AE) was estimated from the slopes of the standard curves using the equation $\mathrm{AE}=10^{\text {-slope }}-1$ (10). The low detection limit (LDL), expressed as copy number, was estimated from the log concentration $\mathrm{Y}$ using the default Ct cutoff at $40(x=40)$ for a respective linear regression. For example, for A. agrostis singleplex qPCR, the LDL in log concentration $\mathrm{Y}=(-0.306 \times 40)+$ $12.753=0.515=\log (\mathrm{LDL})$. Therefore, $\mathrm{LDL}=3.26$ copies.

Statistical analysis. Real-time PCR data were exported from the SmartCycler for calculation of mean $\mathrm{Ct}$ values and standard deviations. Analysis of variance was performed on the means of $\mathrm{Ct}$ values and, when significant, this was followed by a mean comparison test (Tukey's) using a confidence level of $P=0.05$. The statistical analysis for the data (Tables 4 and 5) was performed with SAS (SAS Institute Inc., Cary, NC).

\section{Results}

Analysis of newly obtained Anguina sequences. Fragments of approximately 1,000 bp containing rDNA ITS1, 5.8S rRNA, and

Table 2. TaqMan probes and primers developed and validated for identification of different Anguina spp.

\begin{tabular}{|c|c|c|}
\hline $\begin{array}{l}\text { Probe- } \\
\text { primer } \\
\text { set name }\end{array}$ & $\begin{array}{c}\text { Probe or } \\
\text { primer } \\
\text { name }^{\mathbf{a}}\end{array}$ & $5^{\prime}$ to $3^{\prime}$ sequence \\
\hline \multirow[t]{3}{*}{ AAfpr } & AAf & CGG TTG TTT ACG GCC GT \\
\hline & AAp & $\begin{array}{l}\text { ATC ATG TCT TGG CTA TTG TAG ACG TAT } \\
\text { CTG }\end{array}$ \\
\hline & AAr & ATG TAG TCG GTG TGA AAA CAG CCA T \\
\hline \multirow[t]{3}{*}{ AFfpr } & AFf & GGT TGC TTA CGG CCC \\
\hline & $\mathrm{AFp}$ & $\begin{array}{l}\text { ATC ATG TCT TGG CTA TTA TAG ACG TAT } \\
\text { CTG }\end{array}$ \\
\hline & $\mathrm{AFr}$ & GTG TAA TCG ATG TGA TAC AGC CCC \\
\hline \multirow[t]{3}{*}{ APfpr } & APf & ACC GGT TGA ATA TTG GCT GT \\
\hline & APp & $\begin{array}{l}\text { ATC ATG TCT TGG AAA GTT TAG ACG TAT } \\
\text { CTG }\end{array}$ \\
\hline & APr & ATG TAA TCG ATG TGA AAC AGC CGT \\
\hline \multirow[t]{3}{*}{ ATfpr } & ATf & GTT GCC TAC GGC CGT \\
\hline & ATp & $\begin{array}{l}\text { ATC ATG TCT TGG CTA GTG TAG ACG TAT } \\
\text { CTG }\end{array}$ \\
\hline & $\mathrm{ATr}$ & ATG TAA TCG ATG TGG TAC AGC CAT \\
\hline \multirow[t]{3}{*}{ ASfpr ${ }^{b}$} & ASf & GTC TTA TCG GTG GAT CAC TCG G \\
\hline & ASp & TCA TAG ATC GAT GAA GAA CGC AGC CA \\
\hline & $\mathrm{ASr}$ & TGC AGT TCA CAC CAT ATA TCG CAG \\
\hline
\end{tabular}

a Abbreviations include $\mathrm{A}=$ Anguina + species name (second letter $\mathrm{A}, \mathrm{F}, \mathrm{P}$, or $\mathrm{T}) ; \mathrm{f}=$ forward primer; $\mathrm{p}=$ probe; $\mathrm{r}=$ reverse primer.

b Universal primer-probe set $(\mathrm{A}=$ Anguina $+\mathrm{S}=$ species $)$.
ITS2 were amplified from specimens of A. funesta, A. agrostis, A. tritici, and A. pacificae. GenBank accession numbers for newly obtained DNA sequences from each species are listed in Table 1. Comparison of these sequences with the nonredundant DNA database in GenBank at the National Center for Biotechnology Information (http://www.ncbi.nlm.nih.gov/) confirmed the species identity of each population. With a few exceptions, similarities to previously reported sequences of known Anguina sp. were over 99\% (not shown). Sequence from the undescribed Anguina sp. from Idaho was $96 \%$ similar to A. wevelli (represented by GenBank accession numbers AM8888393 and AF396317) and an anguinid from Stipa (AF396316). The Anguina sp. from Oregon was 93\% similar to A. graminis (AF396351) and 93\% similar to an Anguina sp. from Holcus lanatus (AF396350). This level of similarity is too low to support conspecificity with those populations, because $99 \%$ sequence identity to known Anguina reference sequences is typically expected for a positive identification based on ITS rDNA.

Primer and probe specificity. Based on conserved regions of ITS rDNA, a universal primer pair and TaqMan probe (set ASpfr) were designed to serve as an internal amplification control for all known Anguina spp. (Table 2). DNA regions that were unique to each species were identified and used for the design of primers and probes specific for A. agrostis (set AAfpr), A. funesta (set AFfpr), A. pacificae (set APfpr), and A. tritici (set ATfpr). Primer and probe sequences were each checked for mismatches to all known sequences of the target and nontarget species. For A. pacificae, only one DNA sequence was previously known, covering only the ITS1 region of rRNA. The newly obtained sequence (KM114440) contains a longer span including ITS1, 5.8S, and ITS2 rRNA, thereby providing additional regions from which to design the species-specific primers and probes.

The internal control primer-probe set ASfpr was able to detect all named Anguina spp. tested, with Ct values all less than 25 (Table 3). For the two undescribed species, the Ct values were slightly higher

Table 3. Detection of Anguina and other nematode species by real-time polymerase chain reaction (PCR)

\begin{tabular}{|c|c|c|c|}
\hline Nematode species & Origin & Sample ID & $\begin{array}{c}\text { Mean } \mathrm{Ct} \\
\text { value of } \\
\text { real-time } \mathrm{PCR}^{\mathrm{a}}\end{array}$ \\
\hline \multirow[t]{2}{*}{ Anguina agrostis } & \multirow[t]{2}{*}{ Oregon } & $70 \mathrm{E} 4$ & 24.18 \\
\hline & & 70E5 & 24.35 \\
\hline \multirow[t]{8}{*}{ A. funesta } & \multirow[t]{5}{*}{ Australia } & $70 \mathrm{~F} 1$ & 23.48 \\
\hline & & $70 \mathrm{~F} 2$ & 23.89 \\
\hline & & $70 \mathrm{~F} 3$ & 23.82 \\
\hline & & $70 \mathrm{~F} 4$ & 23.59 \\
\hline & & 70F5 & 23.45 \\
\hline & \multirow[t]{3}{*}{ Oregon } & $49 \mathrm{~F} 4$ & 23.86 \\
\hline & & 49F5 & 23.68 \\
\hline & & $49 \mathrm{~F} 6$ & 23.52 \\
\hline \multirow[t]{2}{*}{ A. pacificae } & \multirow[t]{2}{*}{ California } & $74 \mathrm{C} 1$ & 22.89 \\
\hline & & $74 \mathrm{C} 2$ & 22.67 \\
\hline \multirow[t]{4}{*}{ A. tritici } & \multirow[t]{2}{*}{ Mexico } & $74 \mathrm{~B} 1$ & 23.77 \\
\hline & & 74B2 & 23.65 \\
\hline & Virginia & $16 \mathrm{E} 1$ & 23.82 \\
\hline & North Carolina & $16 \mathrm{~F} 1$ & 23.78 \\
\hline \multirow[t]{4}{*}{ Anguina sp. } & \multirow[t]{2}{*}{ Idaho } & 70G1 & 27.46 \\
\hline & & 70G2 & 27.51 \\
\hline & \multirow[t]{2}{*}{ Oregon } & $70 \mathrm{H} 1$ & 28.12 \\
\hline & & $70 \mathrm{H} 2$ & 28.08 \\
\hline Meloidogyne marylandi & Israel & $49 \mathrm{H} 1$ & 32.18 \\
\hline M. graminis & Florida & $49 \mathrm{E} 7$ & 34.24 \\
\hline M. naasi & United Kingdom & $67 \mathrm{H} 1$ & 33.20 \\
\hline M. minor & United Kingdom & $67 \mathrm{G} 4$ & 33.18 \\
\hline M. hapla & Netherlands & 06K1 & 33.42 \\
\hline Pratylenchus neglectus & Idaho & $37 \mathrm{~A} 1$ & 36.48 \\
\hline P. penetrans & Maryland & $31 \mathrm{G} 8$ & 32.38 \\
\hline Xiphinema americanum & Georgia & 09J1 & 32.20 \\
\hline
\end{tabular}

\footnotetext{
${ }^{a}$ Mean cycle threshold $(\mathrm{Ct})$ value of three real-time PCR results obtained with
} the 5.8S ribosomal DNA-based probe-primer set ASfpr. 
Table 4. Specificity of duplex real-time polymerase chain reaction (PCR) assays for Anguina and nontarget nematode species

\begin{tabular}{|c|c|c|c|c|c|c|c|c|c|}
\hline \multirow[b]{3}{*}{ Nematode species } & \multirow[b]{3}{*}{ Sample } & \multicolumn{8}{|c|}{ Ct value of duplex real-time PCR } \\
\hline & & \multicolumn{2}{|c|}{ AFfpr + ASfpr } & \multicolumn{2}{|c|}{ AAfpr + ASfpr } & \multicolumn{2}{|c|}{ ATfpr + ASfpr } & \multicolumn{2}{|c|}{ APfpr + ASfpr } \\
\hline & & AFfpr & $\overline{\text { ASfpr }}$ & AAfpr & $\overline{\text { ASfpr }}$ & ATfpr & $\overline{\text { ASfpr }}$ & APfpr & $\overline{\text { ASfpr }}$ \\
\hline \multirow[t]{2}{*}{ Anguina agrostis } & $70 \mathrm{E} 4$ & 0.00 & 24.20 & 26.84 & 24.29 & 0.00 & 24.15 & 0.00 & 24.18 \\
\hline & $70 \mathrm{E} 5$ & 0.00 & 24.24 & 27.25 & 24.53 & 0.00 & 24.15 & 0.00 & 24.08 \\
\hline \multirow[t]{8}{*}{ A. funesta } & $70 \mathrm{~F} 1$ & 23.24 & 23.30 & 0.00 & 23.44 & 0.00 & 23.69 & 0.00 & 23.61 \\
\hline & $70 \mathrm{~F} 2$ & 22.95 & 23.35 & 0.00 & 24.05 & 0.00 & 23.87 & 0.00 & 23.99 \\
\hline & $70 \mathrm{~F} 3$ & 23.60 & 23.79 & 0.00 & 23.51 & 0.00 & 23.98 & 0.00 & 23.94 \\
\hline & $49 F 4$ & 23.21 & 23.86 & 0.00 & 23.91 & 0.00 & 24.35 & 0.00 & 24.33 \\
\hline & $70 \mathrm{~F} 4$ & 23.29 & 23.21 & 0.00 & 23.60 & 0.00 & 23.74 & 0.00 & 23.73 \\
\hline & $70 \mathrm{~F} 5$ & 23.40 & 23.37 & 0.00 & 23.37 & 0.00 & 23.83 & 0.00 & 23.89 \\
\hline & $49 F 5$ & 23.38 & 23.36 & 0.00 & 23.65 & 0.00 & 23.55 & 0.00 & 23.72 \\
\hline & $49 \mathrm{~F} 6$ & 23.67 & 23.47 & 0.00 & 23.55 & 0.00 & 23.80 & 0.00 & 23.51 \\
\hline \multirow[t]{2}{*}{ A. pacificae } & $74 \mathrm{C} 1$ & 0.00 & 22.65 & 0.00 & 22.40 & 0.00 & 22.72 & 22.84 & 22.31 \\
\hline & $74 \mathrm{C} 2$ & 0.00 & 22.36 & 0.00 & 22.70 & 0.00 & 22.62 & 23.09 & 22.69 \\
\hline \multirow[t]{4}{*}{ A. tritici } & $74 \mathrm{~B} 1$ & 0.00 & 23.89 & 0.00 & 23.97 & 23.36 & 23.45 & 0.00 & 23.89 \\
\hline & $74 \mathrm{~B} 2$ & 0.00 & 23.72 & 0.00 & 23.84 & 23.51 & 23.51 & 0.00 & 23.50 \\
\hline & $16 \mathrm{E} 1$ & 0.00 & 23.78 & 0.00 & 23.74 & 23.54 & 23.95 & 0.00 & 23.76 \\
\hline & $16 \mathrm{~F} 1$ & 0.00 & 23.89 & 0.00 & 23.87 & 23.37 & 23.60 & 0.00 & 23.58 \\
\hline \multirow[t]{4}{*}{ Anguina sp. } & $70 \mathrm{G} 1$ & 0.00 & 27.20 & 0.00 & 27.56 & 0.00 & 27.62 & 0.00 & 28.08 \\
\hline & $70 \mathrm{G} 2$ & 0.00 & 27.48 & 0.00 & 27.54 & 0.00 & 27.61 & 0.00 & 27.39 \\
\hline & $70 \mathrm{H} 1$ & 0.00 & 28.10 & 0.00 & 28.21 & 0.00 & 27.68 & 0.00 & 28.30 \\
\hline & $70 \mathrm{H} 2$ & 0.00 & 28.71 & 0.00 & 28.34 & 0.00 & 28.66 & 0.00 & 28.36 \\
\hline Meloidogyne marylandi & $49 \mathrm{H} 1$ & 0.00 & 32.06 & 0.00 & 32.33 & 0.00 & 32.43 & 0.00 & 32.25 \\
\hline M. graminis & 49E7 & 0.00 & 33.90 & 0.00 & 34.52 & 0.00 & 32.29 & 0.00 & 34.12 \\
\hline M. naasi & $67 \mathrm{H} 1$ & 0.00 & 34.06 & 0.00 & 34.25 & 0.00 & 34.47 & 0.00 & 34.16 \\
\hline M. minor & $67 \mathrm{G} 4$ & 0.00 & 32.15 & 0.00 & 32.08 & 0.00 & 33.41 & 0.00 & 33.02 \\
\hline M. hapla & 06K1 & 0.00 & 33.24 & 0.00 & 33.40 & 0.00 & 33.51 & 0.00 & 33.46 \\
\hline Pratylenchus neglectus & 37A1 & 0.00 & 36.52 & 0.00 & 36.40 & 0.00 & 36.48 & 0.00 & 36.28 \\
\hline Pratylenchus penetrans & $31 \mathrm{G} 8$ & 0.00 & 32.51 & 0.00 & 32.40 & 0.00 & 32.57 & 0.00 & 32.46 \\
\hline Xiphinema americanum & 09J1 & 0.00 & 31.83 & 0.00 & 32.35 & 0.00 & 30.45 & 0.00 & 32.04 \\
\hline \multirow[t]{2}{*}{ Ditylenchus dipsaci } & $68 \mathrm{H} 10$ & 0.00 & 24.24 & 0.00 & 24.09 & 0.00 & 21.96 & 0.00 & 24.51 \\
\hline & $68 \mathrm{H} 11$ & 0.00 & 25.18 & 0.00 & 23.80 & 0.00 & 22.92 & 0.00 & 23.99 \\
\hline \multirow[t]{2}{*}{ D. destructor } & $05 \mathrm{~J} 7$ & 0.00 & 31.27 & 0.00 & 31.38 & 0.00 & 31.44 & 0.00 & 29.51 \\
\hline & 05J8 & 0.00 & 31.18 & 0.00 & 31.46 & 0.00 & 30.54 & 0.00 & 31.07 \\
\hline \multirow[t]{4}{*}{ Aphelenchoides fragariae } & $80 \mathrm{H} 5$ & 0.00 & 0.00 & 0.00 & 0.00 & 0.00 & 0.00 & 0.00 & 0.00 \\
\hline & $80 \mathrm{H} 6$ & 0.00 & 0.00 & 0.00 & 0.00 & 0.00 & 0.00 & 0.00 & 39.90 \\
\hline & $80 \mathrm{G} 7$ & 0.00 & 0.00 & 0.00 & 0.00 & 0.00 & 0.00 & 0.00 & 38.86 \\
\hline & $80 \mathrm{G} 8$ & 0.00 & 0.00 & 0.00 & 0.00 & 0.00 & 0.00 & 0.00 & 33.65 \\
\hline Water control & $\ldots$ & 0.00 & 0.00 & 0.00 & 0.00 & 0.00 & 0.00 & 0.00 & 0.00 \\
\hline
\end{tabular}

a Each column indicates the primers included and probe detected in each part of the duplex reactions, as indicated by the cycle threshold (Ct) values shown. Abbreviations: AFfpr $=$ A. funesta, ASfpr = Anguina sp. $($ genus-specific internal control $)$, AAfpr $=$ A. agrostis, ATfpr $=$ A. tritici, and APfpr $=$ A. pacificae .

Table 5. Comparisons of amplification efficiency (AE) between single- and duplex real-time quantitative polymerase chain reaction (qPCR) for detection of Anguina spp.

\begin{tabular}{|c|c|c|c|c|c|c|}
\hline Species & qPCR type & Probe-primer set & Linear regressiona & $r^{2 b}$ & $\mathrm{AE}(\%)^{\mathrm{c}}$ & $\overline{\text { LDL }^{d}}$ \\
\hline \multirow[t]{3}{*}{ Anguina agrostis } & Singleplex & AAfpr & $Y=-0.306 x+12.753$ & 0.995 & 102.30 & 3.26 \\
\hline & Duplex & AAfpr & $Y=-0.238 x+12.143$ & 0.980 & 72.98 & 419 \\
\hline & Internal control & ASfpr & $Y=-0.328 x+13.383$ & 0.999 & 112.81 & 1.8 \\
\hline \multirow[t]{3}{*}{ A. funesta } & Singleplex & AFfpr & $Y=-0.325 x+13.268$ & 1.000 & 111.35 & 1.8 \\
\hline & Duplex & AFfpr & $Y=-0.340 x+13.929$ & 0.997 & 118.78 & 2.13 \\
\hline & Internal control & ASfpr & $Y=-0.341 x+13.877$ & 0.997 & 117.09 & 1.8 \\
\hline \multirow[t]{3}{*}{ A. pacificae } & Singleplex & APfpr & $Y=-0.329 x+13.256$ & 0.999 & 113.30 & 1.25 \\
\hline & Duplex & APfpr & $Y=-0.334 x+13.196$ & 0.998 & 115.77 & 0.68 \\
\hline & Internal control & ASfpr & $Y=-0.334 x+13.132$ & 0.998 & 113.77 & 0.59 \\
\hline \multirow[t]{3}{*}{ A. tritici } & Singleplex & ATfpr & $Y=-0.313 x+13.035$ & 0.998 & 105.60 & 3.27 \\
\hline & Duplex & ATfpr & $Y=-0.270 x+12.403$ & 0.996 & 86.21 & 40.08 \\
\hline & Internal control & ASfpr & $Y=-0.304 x+12.809$ & 1.000 & 101.37 & 4.46 \\
\hline
\end{tabular}

${ }^{a}$ Linear regressions $(Y=a+b x)$ were calculated from standard curves, plotting the log concentration of the template copies $(Y)$ versus the mean cycle threshold $(\mathrm{Ct})$ values $(x)$ with slope value $(b)$.

$\mathrm{b}$ Indicates how well the linear equation fits the data and is an indicator of reaction efficiency.

c $\mathrm{AE}(\%)=10^{- \text {slope }}-1(9)$.

${ }^{\mathrm{d}} \mathrm{LDL}=$ low detection limit: Equivalent copy number estimated from the log concentration $\mathrm{Y}$ using the default Ct cutoff at 40 ( $\left.x=40\right)$ for a respective linear regression. For example, for A. agrostis singleplex qPCR, the LDL in log concentration $Y=(-0.306 \times 40)+12.753=0.515=10 g(\mathrm{LDL})$. Therefore, $\mathrm{LDL}=3.26$ copies 
(27.46 to 28.12), which is consistent with the presence of $1 \mathrm{bp}$ mismatch in the probe ASp compared with the DNA sequence of Anguina sp. from Oregon and $1 \mathrm{bp}$ mismatch in primer ASr compared with Anguina sp. from Idaho (Table 2). Ct values were over 32 for all of the nontarget species, which was consistent with weaker primer and probe binding to non-Anguina spp. due to the presence of several mismatched bases. The specificity of primer-probe sets AAfpr, AFfpr, APfpr, and ATfpr was tested in singleplex reactions against target and nontarget Angina spp. and other species of nematodes (not shown). All primer-probe set specificity was tested in duplex real-time PCR, in which each species-specific primer-probe set was tested in the same reaction as the genus-specific set ASfpr (Table 4). As expected, the species-specific primer-probe sets reacted only with their intended target species and did not react with nontarget Anguina spp., giving zero Ct values. Ct values averaged 23.34 for A. funesta, 27.05 for A. agrostis, 23.45 for A. tritici, and 22.97 for A. pacificae. There were no significant differences in species-specific primer-probe $\mathrm{Ct}$ values between the single (not shown) or duplex (Table 4) reactions. The ASfpr primer-probe set gave fairly consistent $\mathrm{Ct}$ values in the duplex reactions (Table 4), ranging from 22.31 to 24.53 for named Anguina spp., with a high Ct score of 28.36 for Anguina spp. Ct values $>30$ occurred for most nontarget species with ASfpr, except for D. dipsaci (21.96 to 25.18). Most of the A. fragariae reactions were negative, except for ASfpr in the presence of APfpr. Nontemplate negative controls gave zero Ct values.

PCR AE and LDL. Standard curves were constructed from realtime PCR performed with serial 10-fold dilutions of Anguina spp. DNA template (Table 5; curves not shown). These experiments included singleplex quantitative (q)PCR with species-specific primerprobe sets for A. funesta (AFfpr), A. agrostis (AAfpr), A. tritici (ATfpr), or A. pacificae (APfpr) and duplex qPCR with the species-specific primer-probe sets and the genus specific ASfpr primer-probe set as an internal control. In each standard curve, there was a strong negative relationship between $\mathrm{Ct}$ and log-transformed amounts of Anguina DNA, with $r^{2}$ values for all curves at or near 1.0 (Table 5). In comparison with singleplex PCR assays, the PCR $\mathrm{AE}$ of the primer-probe sets AFfpr for A. funesta and APfpr for A. pacificae were not significantly different from their duplex reactions. Although the AE of the primer-probe set ATfpr for A. tritici was also reduced in its duplex reaction, it still remained above the $85 \%$ level suitable for use in diagnosis (11). However, the AE of the primerprobe set AAfpr for A. agrostis was greatly reduced from 102.8 to $72.9 \%$ in its duplex reaction. This suggests that the duplex primer and probe combination may be less desirable for detection of A. agrostis. Results of the dilution series experiments indicate that the LDL of the singleplex reactions was as low as 1.25 copies of the ITS 1 gene (A. pacificae) and as low as 0.68 copies (A. pacificae) in the duplex reactions. LDL for the duplex reactions of $A$. agrostis and $A$. tritici were higher than for the singleplex reactions (Table 5), which is consistent with the lower AE observed in those duplex reactions.

\section{Discussion}

Until now, Anguina spp. of economic and regulatory importance were primarily identified through a combination of morphological measurements and PCR RFLP of ITS amplification products (15). Indistinct juvenile morphology may confound identification in the frequent instances where no adults are found in seed galls, leading to potential regulatory complications. Sequencing of the ITS1 and -2 rDNA genes followed by database searches, alignments, and phylogenetic analysis is also used for unambiguous identification of Anguina spp., particularly when a new or unnamed species is suspected (21). However, this approach is relatively labor intensive and would likely be prohibitively expensive and impractical in a diagnostic setting where large numbers of samples need to be processed.

This study represents the first demonstration of species-specific real-time PCR primers and probes for identification and detection of four major Anguina spp. For each primer-probe set designed for A. agrostis, A. funesta, A. pacificae, and A. tritici, only the species targeted gave positive $\mathrm{Ct}$ values in real-time PCR; tests performed with nontarget species were negative (Table 4). The genus-level primer-probe set ASfpr gave similarly low $\mathrm{Ct}$ values against named Anguina spp.; this component of the reaction served as a positive internal control for the presence of intact template DNA, integrity of the PCR components, cycler performance, and operator performance. The ability of ASfpr to react with nontarget species was variable; species phylogenetically close to Anguina such as $D$. dipsaci gave fairly low $\mathrm{Ct}$ values, while the phylogenetically distant $A$. fragariae reacted very poorly with the Anguina-specific ASfpr primer set (Table 4, some $\mathrm{Ct}=0$ ). A TaqMan assay for detection of Meloidogyne chitwoodi and M. fallax also contained such an internal amplification control, which is useful for quality control in the diagnostics of quarantine organisms (25).

Only one other study published to date included a real-time PCR assay for Anguina sp. identification (11), and was designed only to $\operatorname{detect} A$. agrostis. The primers and TaqMan probe targeted the same region of ITS1 as the primers and probe described in the present study; their assay was positive when tested against $A$. agrostis but negative for A. tritici, A. wevelli, and D. destructor (11). Although there was partial overlap in the region of ITS1 targeted by their A. agrostis primers and ours, their primer-probe set could be tested in our duplex assay to determine whether there is any improvement in reaction efficiency in the A. agrostis duplex reaction. Alternatively, additional annealing temperatures, use of three-step versus two-step cycling conditions, or altered primer concentration ratios may be investigated to further improve performance of the AAfpr primer-probe set for detecting A. agrostis. For all species-specific primers tested and for the genus-specific primer set, there was a strong linear correlation between the quantity of template DNA present and the $\mathrm{Ct}$ values (Table 5; standard curves not shown). With the exception of A. agrostis, the Ct values for AFfpr, APfpr, and ATfpr were all less than 25 , indicating that the single nematode extracts tested contained at least 1,000 copies of the target DNA. This is well above the LDL determined for those primer-probe combinations, whether in duplex or single reactions (Tables 4 and 5). Therefore, the sensitivity of the reactions is sufficient to identify the target species at a much lower concentration of template DNA than would be necessary to produce sufficient PCR product to detect the smallest DNA fragments from PCR-RFLP on an agarose gel (15). Thus, this method represents a higher sensitivity than the only other nonsequencingbased method of Anguina sp. identification.

The present method provides a basis for development of standardized protocols that could be very useful for processing large numbers of survey samples or others that require identification in regulatory settings. The ability to quickly and clearly discriminate among A. funesta, A. agrostis, A. tritici, and A. pacificae provides muchneeded tools for accurate identification of these species. Although other Anguina spp. or unnamed populations were unavailable for specificity testing in our assay, extensive in silico analysis of the primers and probes indicated that false-positive reactions are unlikely. If the results of our assay are negative or inconclusive for an unknown population, sequencing of the ITS region could still be used to support morphological identifications. Expansion of studies to characterize additional unnamed species that may be associated with harmful bacteria will further strengthen the diagnostics needed for accurate identification of Anguina.

\section{Acknowledgments}

We thank M. McClure (University of Arizona) and C. Fraley (Oregon Department of Agriculture) for providing Anguina specimens, Z. Handoo (Nematology Laboratory, USDA-ARS Beltsville, MD) for morphological confirmation of species identities, and M. Hult and J. Mowery for excellent technical assistance.

\section{Literature Cited}

1. Alderman, S. C., Ocamb, C. M., and Mellbye, M. E. 2005. Quantitative assessment of Anguina sp. and Rathayibacter rathayi in Dactylis glomerata seed production fields in Oregon and estimates of yield loss. Plant Dis. 89: 1313-1316.

2. Cheeke, P. R. 1995. Endogenous toxins and mycotoxins in forage grasses and their effects on livestock. J. Anim. Sci. 73:909-918.

3. Eisenback, J. D., and Roane, C. W. 2006. First report of bentgrass seed gall nematode, Anguina agrostis, in Virginia and Minnesota. Plant Dis. 90:1110. 
4. Fisher, J. M. 1978. Annual Ryegrass Toxicity. Waite Institute Biennial Report. Waite Agricultural Research Institute, Glen Osmond, SA, Australia.

5. Fisher, J. M., Dube, A. J., and Watson, C. M. 1979. Distribution in South Australia of Anguina funesta, the nematodes associated with annual ryegrass toxicity. Aust. J. Exp. Agric. Anim. Husb. 19:48-52.

6. Howlett, B. J., Brownlee, A. G., Guest, D. I., Adcock, G. J., and McFadden, G. I. 1992. The 5S ribosomal RNA gene is linked to large and small subunit ribosomal RNA genes in the oomycetes, Phytophthora vignae, P. cinnamomi, P. megaspera f. sp. glycinae and Saprolegnia ferax. Curr. Genet. 22:455-461.

7. Joyce, S. A., Reid, A., Driver, F., and Curran, J. 1994. Application of polymerase chain reaction (PCR) methods to identification of entomopathogenic nematodes. Pages 178-187 in: COST 812 Biotechnology: Genetics of Entomopathogenic Nematode-Bacterium Complexes. A. M. Burnell, R.-U. Ehlers, and J. P. Masson, eds. Proc. Symp. Workshop, St. Patrick's College, Maynooth, Co. Kildare, Ireland. European Commission, DG XII, Luxembourg.

8. De Weerdt, M., Kox, L., Waeyenberge, L., Viaene, N., and Zijlstra, C. 2011. A real-time PCR assay to identify Meloidogyne minor. J. Phytopathol. 159: 80-84.

9. Lehman, P. S. 1979. Seed and leaf gall nematodes of the genus Anguina occurring in North America. Nematol. Circ. No. 55, Sept. 1979. Florida Department of Agriculture, Division of Plant Industry, Gainesville, FL.

10. Li, W., Li, D., Twig, E., Hartung, J. S., and Levy, L. 2008. Optimized quantification of unculturable Candidatus Liberibacter spp. in host plants using real-time PCR. Plant Dis. 92:854-861.

11. Ma, Y., Xie, H., Wang, J., and Lui, C. 2011. Detection of second-stage juveniles of Anguina agrostis using TaqMan real-time PCR. Russ. J. Nematol. 19:151-158.

12. McClure, M. A., Schmitt, M. E., and McCullough, M. D. 2008. Distribution, biology and pathology of Anguina pacificae. J. Nematol. 40:226-239.

13. Meng, S., Alderman, S., Fraley, C., Ludy, R., Sun, F., and Osterbauer, N. 2012. Identification of Anguina funesta from annual ryegrass seed lots in Oregon. Online publication. Plant Health Prog. doi:10.1094/PHP-2012-1024-01-RS

14. Nakhla, M. K., Owens, K. J., Li, W., Wei, G., Skantar, A. M., and Levy, L. 2010. Multiplex real-time PCR assays for identification of the potato cyst and tobacco cyst nematodes. Plant Dis. 94:959-965.
15. Powers, T. O., Szalanski, A. L., Mullin, P. G., Harris, T. S., Bertozzi, T., and Griesbach, J. A. 2001. Identification of seed gall nematodes of agronomic and regulatory concern with PCR-RFLP of ITS1. J. Nematol. 33:191-194.

16. Riley, I. T., Gregory, A. R., Allen, J. G., and Edgar, J. A. 2003. Poisoning of livestock in Oregon in the 1940s to 1960s attributed to corynetoxins produced by Rathayibacter in nematode galls in chewings fescue (Festuca nigrescens). Vet. Hum. Toxicol. 45:160-162.

17. Riley, I. T., Schmitz, A., and De Silva, P. 2001. Anguina australis, a vector for Rathayibacter toxicus in Ehrharta longiflora. Australas. Plant Pathol. 30: 171-175.

18. Sayler, R. J., Walker, C., Goggin, F., Aguldelo, P., and Kirkpatrick, T. 2012 Conventional PCR detection and real-time PCR quantification of reniform nematodes. Plant Dis. 96:1757-1762.

19. Skantar, A. M., Handoo, Z. A., Zanakis, G. N., and Tzortzakakis, E. A. 2012 Molecular and morphological characterization of the corn cyst nematode, Heterodera zeae, from Greece. J. Nematol. 44:58-66.

20. Stynes, B. A., and Bird, A. F. 1982. Development of galls induced in Lolium rigidum by Anguina agrostis. Phytopathology 72:336-346.

21. Subbotin, S. A., Krall, E. L., Riley, I. T., Chizhov, V. N., Staelens, A., De Loose, M., and Moens, M. 2004. Evolution of the gall-forming plant parasitic nematodes (Tylenchida: Anguinidae) and their relationship with hosts as inferred from internal transcribed spacer sequences of nuclear ribosomal DNA. Mol. Phylogenet. Evol. 30:226-235.

22. Thomas, W. K., Vida, J. T., Frisse, L. M., Mundo, M., and Baldwin, J. G. 1997. DNA sequences from formalin-fixed nematodes: Integrating molecular and morphological approaches to taxonomy. J. Nematol. 29: 250-254.

23. Vargas, O. F., and Sasser, J. N. 1976. Biology of Anguina plantaginis parasitic on Plantago aristata. J. Nematol. 8:64-68.

24. Yan, G., Smiley, R. W., Okubara, P. A., Skantar, A. M., and Reardon, C. L. 2013. Developing a real-time PCR assay for detection and quantification of Pratylenchus neglectus in soil. Plant Dis. 97:757-764.

25. Zijlstra, C., and Van Hoof, R. A. 2006. A multiplex real-time polymerase chain reaction (TaqMan) assay for the simultaneous detection of Meloidogyne chitwoodi and M. fallax. Phytopathology 96:1255-1262. 